\title{
UMA NARRATIVA SOBRE A EXTENSÃO UNIVERSITÁRIA NO CONTEXTO DA QUARTA REVOLUÇÃO INDUSTRIAL: AS OPORTUNIDADES PARA O DESENVOLVIMENTO DE COMPETÊNCIAS SOCIOEMOCIONAIS
}

\author{
A NARRATIVE ON THE UNIVERSITY EXTENSION IN THE CONTEXT OF THE FOURTH \\ INDUSTRIAL REVOLUTION: A SOFT SKILLS DEVELOPMENT
}

Thiago Henrique Almino Francisco ${ }^{1}$, Leticia Silva da Cunha ${ }^{1}$, Isadora Maria Back da Veiga ${ }^{1}$

\section{RESUMO}

A extensão no ensino superior tem sido considerada um elemento substancial para o desenvolvimento de oportunidades de inovação pedagógica e curricular. Nesse sentido, considerando-a como um instrumento aplicado ao desenvolvimento de competências, este artigo tem o objetivo de conhecer as contribuições da extensão para o desenvolvimento de competências socioemocionais em jovens que residem em espaços de vulnerabilidade social. Por meio de uma pesquisa de abordagem narrativa, com participantes de um projeto de extensão que ocorre em uma Universidade Comunitária Catarinense, foi possível identificar as contribuições proporcionadas na formação de indivíduos que participaram do projeto. As considerações finais asseveram a extensão como uma estratégia de aprendizagem que pode fortalecer os currículos no ensino superior e fomentar inovações, por parte das Instituições que a adotam como estratégia curricular.

Palavras-Chave: Ensino Superior. Extensão. Competências Socioemocionais.

\begin{abstract}
Extension in higher education has been considered a substantial element in the development of opportunities for pedagogical and curricular innovation. In this sense, considering it as an instrument applied to the development of skills, this article aims to understand the contributions of extension to the development of socio-emotional skills in young people living in socially vulnerable spaces. Through a research of narrative approach, with participants of an extension project that takes place at a Community University in Santa Catarina, it was possible to identify the contributions provided in the training of individuals who participated in the project. Final considerations assert extension as a learning strategy that can strengthen curricula in higher education and foster innovation, on the part of the Institutions that adopt it as a curriculum strategy.
\end{abstract}

Keywords: Higher Education. Extension. Socioemotional Competencies.

\footnotetext{
${ }^{1}$ Universidade do Extremo Sul Catarinense - UNESC
} 


\section{INTRODUÇÃO}

$\mathrm{O}$ ensino superior tem percorrido trajetórias distintas em função das demandas apresentadas pelo atual contexto, que é fervorosamente influenciado pela tecnologia e pelas novas demandas de trabalho. Isso desperta um processo de ressignificação dos currículos, estabelecendo um conjunto de práticas que tem o objetivo de (re) construir o percurso formativo do estudante em seu processo de formação. No mesmo sentido, há também um movimento que amplia o escopo da Universidade, tornando-a uma estrutura que é responsável por fomentar relações interdependentes entre a formação e as demandas sociais. Nesse trajeto, a extensão cumpre um papel fundamental, como sendo a principal ferramenta que proporciona a interação entre o ensino superior e as demandas sociais.

Em um cenário de mudanças, tais como o que é encontrado a partir do contexto da Quarta Revolução Industrial, é possível perceber que a extensão também pode ser reconhecida como uma ferramenta aplicada para o desenvolvimento de competências. Sejam elas aplicadas ao mundo do trabalho ou a formação do cidadão, por meio da extensão elas têm a condição também de criar um caminho de retroalimentação do currículo, ampliando o escopo do Projeto Pedagógico de um Curso.

Sob a ótica destas premissas, o artigo tem o objetivo de conhecer as contribuições da extensão para o desenvolvimento de competências socioemocionais em jovens que residem em espaços de vulnerabilidade social. Por meio de uma investigação de abordagem narrativa, os resultados da pesquisa, realizada com participante de um projeto de extensão desenvolvido por uma Universidade Comunitária; que neste estudo será denominada de "IES"; demonstram que a extensão tem sido um mecanismo de fomento de novas capacidades que permitem, inclusive, a ampliação das condições sociais dos envolvidos.

Do ponto de vista das contribuições, espera-se que o trabalho amplie as discussões sobre a extensão e suas possibilidades, numa perspectiva de compreender sua relevância quando integrada a programas e projetos estruturados em um contexto institucional. Dessa forma, emerge a relevância do estudo, sobretudo em função de um movimento que começa a ganhar corpo em virtude dos referenciais nacionais de extensão, que foram publicados ainda no ano de 2018.

Para tanto, o artigo se organiza em cinco seções. Após a primeira, que apresenta a introdução, estão as contribuições da teoria e os procedimentos metodológicos. Segue, posteriormente, os resultados e, por fim, as considerações finais que apresentam as conclusões, as contribuições e as sugestões para os trabalhos futuros. 


\section{CONTRIBUIÇÕES TEÓRICAS}

Neste capítulo encontram-se expostos os dados das buscas sistemáticas que proporcionaram a construção de um quadro teórico sobre o tema. Os conceitos emergiram e foram organizados em eixos que contribuem para explicar o movimento constituído nesta pesquisa.

\subsection{A quarta revolução industrial: uma abordagem teórica}

No contexto atual, emergem discussões que procuram compreender o movimento desencadeado pela tecnologia e que orienta a atividade de organizações das mais diversas naturezas, considerando seus aspectos estruturais e de funcionamento. Na visão de Schwab (2016), isso é resultado do que se denominou de "Quarta Revolução Industrial”, que se caracteriza pela integração da produção industrial com a tecnologia, estabelecendo um movimento que originou as "organizações inteligentes", responsáveis pela produção de soluções que integram o domínio físico e o tecnológico, que geram novas soluções articuladas com os objetivos estratégicos das organizações.

Esse movimento proporcionou condições para que as empresas e organizações, dos mais variados fins, pudessem redirecionar suas capacidades para o uso de novos recursos, com a condição de estruturar soluções tecnológicas articuladas com suas estratégias, fomentando interações que possam gerar produtos que utilizem diversos desdobramentos tecnológicos possíveis. No campo da gestão organizacional, por exemplo, surgem soluções que utilizam da robótica, da impressão 3D, do "Big data", da computação em nuvem e da inteligência artificial, como alternativas aos produtos e soluções convencionais, que podem gerar resultados exponenciais às organizações.

Na perspectiva conceitual, o panorama teórico tem apresentado um movimento que busca explicar as causas e consequências dessa abordagem para as organizações, o que permite inferir que essa abordagem tem se constituído também como um roteiro articulado com a revisão da estratégia das organizações e, até mesmo, algo que propõe um novo posicionamento para uma série de modelos de negócios. Em linhas gerais, o que se percebe é que o cenário tecnológico proporcionado por este contexto é objeto de apropriação das organizações para o desenvolvimento de novas capacidades. 
Nas contribuições de Xiong et. al. (2015), é possível perceber que o engajamento proporcionado por esse novo contexto gera oportunidades de adaptações das organizações tradicionais e fortalece as competências para a segurança das informações estratégicas, que se tornam cada vez mais diferenciadas em um ambiente fortemente influenciado pela tecnologia. A quarta revolução industrial, portanto, altera profundamente as redes de relacionamentos internos da empresa e fomenta práticas de gestão do conhecimento na organização, especialmente para que seja possível desenvolver ativos de conhecimento que potencializem as atividades dos sistemas organizacionais. Surgem, portanto, aplicações tecnológicas de larga escala que redirecionam os aspectos estruturais e tecnológicos das organizações, alterando o paradigma da oferta de soluções para a sociedade.

Fulga, Davidescu e Effenberger (2017), destacam que a quarta revolução industrial introduziu novos princípios nas organizações, permitindo o desenvolvimento de conhecimentos aplicados à produção de soluções sociais. Isso permitiu a oportunidade de explorar outros campos e estabeleceu o desenvolvimento de uma atividade direcionada ao atendimento de contextos específicos. As organizações, portanto, tornaram-se mais eficientes, na medida em que tiveram condições de redirecionar suas capacidades para atender processos de negócios de interesse de um determinado segmento.

Em consonância a essa visão, Balashova e Gramova (2018) destacam que a quarta revolução industrial tem a condição de fomentar o que as autoras denominaram de "manufatura ágil”, já que promove uma transformação radical na estrutura de negócio das indústrias, proporcionando mais interação, flexibilidade e o desenvolvimento de novas formas de operação. Em função da amplitude dos recursos proporcionados, desenvolvem-se novas competências que permitem estruturar um conjunto de estratégias e capacidades dinâmicas, que são aplicadas para mudar as expectativas dos consumidores, aumentar a performance dos produtos e fomentar parcerias entre distintos modelos de negócio, com o objetivo de aumentar a eficiência das organizações.

Essa nova perspectiva gera, portanto, novas condições e capacidades organizacionais que devem ser avaliadas com critérios para que se torne possível alinhar condições para o desenvolvimento das competências das pessoas, que atuam nessas estruturas. Nesse sentido, emergem discussões que visam conhecer as competências necessárias para que as pessoas tenham condições de ocupar espaços estratégicos nessas organizações, especialmente em função da influência da "robótica", em substituição a atividades de pouco valor agregado. Nessa perspectiva, vem a superfície o conceito de "soft skills", também discutidos na 
perspectiva das competências socioemocionais, como alternativa ao desenvolvimento das pessoas em contextos fortemente influenciados pelos impactos da quarta revolução industrial.

2.2 As competências socioemocionais: uma abordagem relacionada com as soft skills

Os desdobramentos identificados no contexto da quarta revolução industrial fomentam novas reflexões a respeito de um movimento que se constitui como necessário para compreender o que está acontecendo no entorno das organizações. Em função do impacto profundo no contexto das organizações, promovido pela influência tecnológica, emergem discussões que buscam compreender os impactos disso no comportamento das pessoas e nas suas capacidades de inserirem na sociedade.

Vale (2009) desenvolve uma reflexão aderente a este aspecto, na medida em que evidencia a necessidade de fomentar novas capacidades sociais nos indivíduos, onde a tecnologia vai rearranjando os espaços organizacionais e sociais. A autora destaca que é o momento de reconstrução do sujeito, para que ele se torne relevante em um contexto em que a tecnologia emerge como instrumento que pode "re" construir o espaço social. Portanto, as capacidades análogas à inteligência emocional, surgem como elementos que conectam o indivíduo a essa "nova sociedade", eivada de instrumentos de tecnologia da informação.

Numa perspectiva gerencial, Aires, Moreira e Freire (2018), destacam que o movimento da indústria 4.0 tem alterado profundamente as formas pelas quais produzimos e nos relacionamos, determinando que novas capacidades devem ser desenvolvidas para que seja possível "re" posicionar o indivíduo na sociedade e no ambiente organizacional. Os trabalhos consultados pelos autores destacam que há evidências de um movimento de educação continuada e formação baseada em capacidades que as máquinas não possuem, especificamente relacionadas à inteligência emocional, a criatividade, a inovação, a solução de problemas e a um conjunto de conhecimentos técnicos que tornam o sujeito um "especialista humanizado".

Em consonância com a obra de Schwab (2016), emergiram diversos estudos com a intenção de desvendar a dinâmica das soft skills, numa tentativa de diferenciá-las das hard skills; consideradas capacidades operacionais aplicadas a produtividade. Calanca et. al. (2019), Sridharan e Boud (2019), Tseng e Yeh (2019), Jagannathan, Camasso e Delacalle (2019), GeorgeouGouras e Nikolau (2019), Rana e Há-Brookshire (2019), entre outros, destacam que a Soft Skills se constituem em capacidades individuais que tem a condição de 
fortalecer a inserção social e organizacional do indivíduo em um contexto de tecnologias alternativas, inteligência artificial e mudança dos paradigmas sociais. Em uma reflexão sobre a obra dos autores, o que se percebe é que há um movimento social estabelecido, e não apenas em países desenvolvidos, que buscam fomentar uma nova sociedade baseada em capacidades de relacionamento e de inserção na sociedade, como alternativa a um cenário emergente que apregoa as competências empreendedoras como formas de alterar a estrutura social.

Para Liventsova, Rumyantseva e Syryramkina (2019), estes elementos são, em verdade, capacidades sociais e humanísticas que qualificam as atividades profissionais, diferenciando-as de operações mecânicas e técnicas, proporcionando uma maior condição do indivíduo desenvolver alternativas de atuar na sociedade e nas organizações. Seguindo a perspectiva de Vale (2009), o trabalho destaca que o contexto da quarta revolução industrial enseja conhecimento e a gestão das próprias emoções, as capacidades de desenvolver habilidades de expressão, de resistência a frustração e de gerar emoções positivas. Além disso, emergem também as capacidades de controlar a produtividade a partir de habilidades de automotivação e de empatia, que torna o indivíduo cada vez mais apto a gerenciar seus relacionamentos.

Para além de questões de viés econômico, o que propõe o Mitchell, Skiner e White (2010), á aderente e alinhado a proposição de Vale (2009), sobre as competências socioemocionais, e pode ser considerado como elemento norteador de novas práticas educacionais e organizacionais, em que se destacam os aspectos que podem se expressar da seguinte forma:

- Habilidades cognitivas: flexibilidade cognitiva, criatividade, raciocínio lógico, sensibilidade para problemas, raciocínio matemático e visualização;

- Habilidades físicas: força física e destreza manual e de precisão;

- Competências de conteúdo: aprendizagem ativa, expressão oral, compreensão de leitura, expressão escrita e alfabetização TIC;

- Competências de processo: escuta ativa, pensamento crítico, monitoramento próprio e dos outros.

- Competências sociais: coordenador de equipe, inteligência emocional, negociação, persuasão, orientação de serviço e treinamento pessoal;

- Competências sistémicas: julgamento de tomada de decisão e análise sistêmica; 
- Competência para solucionar problemas complexos: solução de problemas complexos;

- Competências de Gestão de Recursos: gerenciamento de recursos financeiros, gerenciamento de recursos naturais, gestão de pessoas e gestão de tempo;

- Competências técnicas: reparo e manutenção de equipamentos, controle e operação de equipamentos, programação controle de qualidade.

Portanto, de acordo com o Mitchell, Skiner e White (2010), as Soft Skills são percebidas como elementos altamente relevantes para o novo contexto organizacional que se forma, na medida em que se apontam como aspectos que inferem na personalidade das pessoas em um mundo cada vez mais tecnológico, permitindo a condição de separar habilidades operacionais das humanas, o que dá a condição das organizações, especialmente aquelas que surgem a partir do conceito das "startups", construírem alternativas para promover capacidades diferenciadas nas pessoas, que possam torna-las, tal como Hammel (2012) evidencia, empregáveis em um contexto de fortes mudanças.

\subsection{A extensão como forma de desenvolvimento de competências}

Em tempos de mudança, as adaptações necessárias as contingências organizacionais e sociais ocorrem nos mais diversos segmentos, que se articulam para se (re) inventar para atender a demandas que emergem das inovações que podem acometer a sociedade. No contexto educacional, mais especificamente no ensino superior, isso não é diferente e pode ser compreendido a partir da reflexão sobre as práticas de extensão, notadamente reconhecidas como uma forma de ampliar o diálogo entre a instituição de ensino superior.

A extensão no Brasil é conhecida como um aspecto constitucional para as Universidades e reconhecida como um elemento indutor da qualidade para as IES não universitárias, que permite, por meio de um viés intervencionista, o desenvolvimento de movimentos de aprendizados que compreendem todos os envolvidos no contexto institucional, o que ocorre por meio de ações, projetos ou programas, desde que articulados com as diretrizes institucionais. Do ponto e vista internacional, diversos estudos tem discutido a extensão como um movimento articulado com o desenvolvimento de redes institucionais de fomento a uma série de práticas acadêmicas, que vão desde a pesquisa até a gestão. Nos 
trabalhos de Henderson (2019), Das e Das (2019), Schwab (2016) é possível perceber um movimento que guarda algumas características e tendências extensionistas em nível mundial, mas que também proporcionam oportunidades de aprendizagem diferenciadas aos acadêmicos, numa perspectiva de desenvolvimento de competências.

Considerando trabalhos nacionais, percebe-se que diversos estudos buscam "assentar" a identidade da extensão no ensino superior brasileiro, sobretudo pelo fato de que o conceito da extensão não é regulado como o do ensino e da pesquisa; que ocorre, respectivamente, pelas ações do INEP (com o ENADE) e da CAPES. Muito embora a extensão esteja imbricada com ambos os elementos, em função de sua capacidade de promover a inserção social, há estudos que visam se debruçar sobre o conceito de uma forma mais sistemática. No caso da proposta de Nunes e Silva (2011), é possível identificar que a extensão se configura como um movimento que proporciona diálogo entre a instituição e a sociedade, a partir de ações propositivas e intervencionistas que considerem as diretrizes institucionais e as necessidades da sociedade. Os resultados demonstram a condição de transformar estudantes e representantes da sociedade em participes protagonistas da transformação social, tirando-os da condição de espectadores das mudanças necessárias à sociedade.

Na perspectiva descrita por Rodrigues et. al. (2013), percebe-se que a extensão é uma forma de ampliar as possibilidades de aprendizagem dos estudantes, por meio de práticas que se conectam com as necessidades emergentes da sociedade. Por meio da extensão, tal como discutem os autores, é que se torna possível conduzir a aprendizagem dos estudantes para situações reais, que tem a condição de fomentar competências que sejam relevantes para a inserção social do futuro profissional.

Nesta trilha, é que o Brasil (2018) se posiciona para apresentar uma tentativa de regulamentação das práticas de extensão, percebendo-as como:

\footnotetext{
a atividade que se integra à matriz curricular e à organização da pesquisa, constituindo-se em processo interdisciplinar, político educacional, cultural, científico, tecnológico, que promove a interação transformadora entre as instituições de ensino superior e os outros setores da sociedade, por meio da produção e da aplicação do conhecimento, em articulação permanente com o ensino e a pesquisa. (Brasil, 2018. p. 4)
}

Sob a ótica destas contribuições, portanto, a seguir são apresentados os ordenamentos metodológicos que permitiram identificar as contribuições da extensão para o desenvolvimento de competências socioemocionais em jovens que residem em espaços de vulnerabilidade social, mote principal deste artigo. 


\section{PROCEDIMENTOS METODOLÓGICOS}

Para atingir os resultados propostos neste estudo, optou-se por uma abordagem de cunho interpretativo, numa perspectiva qualitativa, na medida em que a intenção dos resultados é proporcionar uma visão dos elementos norteadores da problemática considerando a participação ativa e protagonista dos sujeitos envolvidos. Nesse sentido, valoriza-se a visão de mundo do sujeito, como ator principal da construção do conhecimento advindo de sua interação com o ambiente, considerando os aspectos simbólicos de sua percepção do mundo. (MORGAN, 1980; CORBIN E STRAUSS, 2008; CRESWELL 2014).

Por isso, o estudo se desenvolve a partir de uma abordagem narrativa, considerando a visão de Creswell (2014), quando ele destaca o fato de que é uma forma de conhecer, sob a ótica da visão dos sujeitos que estão imersos no fenômeno, o movimento caracterizado por algum evento que tenha significado para os sujeitos envolvidos. Dessa forma, a narrativa se mostra como uma forma de descortinar desafios que existem em um dado contexto a partir da visão "tácita" do sujeito, permitindo que se extraiam significados legítimos de um determinado processo social. Ao considerar também a classificação proposta por Flick (2008), importa destacar que esta pesquisa se caracteriza por analisar um contexto episódico, considerando narrativas que buscam discutir um fenômeno específico e pontual.

Buscou-se conhecer a narrativa de participantes de um projeto de extensão que é desenvolvido por uma Universidade Comunitária, que neste estudo será denominada de "IES", e que possui o objetivo de proporcionar o desenvolvimento de Soft Skills para a formação cidadã e autônoma, em contextos de vulnerabilidade social, para cidadãos em idade escolar. O Projeto, desenvolvido na perspectiva de um programa de extensão da Universidade, que é denominado de "Território Paulo Freire", é aplicado em uma escola de ensino fundamental, localizada em um espaço de vulnerabilidade social em um município do extremo sul de Santa Catarina. Atualmente, cerca de 16 jovens, em idades que variam de 14 a 16 anos, participam do projeto. Os Termos de Consentimento Livre e Esclarecido (TCLE), alinhado com a Resolução CNS 466/2012, foram devidamente assinados pelos responsáveis legais dos estudantes, avalizados pela Orientadora Pedagógica da Escola.

Os dados foram coletados a partir de uma entrevista semi-estruturada, aplicada em um conjunto de cinco participantes que se disponibilizaram como voluntários, após um período de sensibilização que ocorreu na metade das atividades do projeto, desenvolvido a partir de um cronograma anual. O roteiro contou com 12 perguntas abertas, todas elas 
alinhadas com a problemática elencada na pesquisa. As entrevistas, com duração aproximada de 35 minutos, gravadas e transcritas, foram analisadas com base nas considerações de Bardin (1977) e Creswell (2014), proporcionando a possibilidade de se estabelecer categorias temáticas que tenham a condição de descrever a narrativa dos pesquisados. Por meio delas, emergiram histórias, epifanias e materiais contextuais que foram organizados em torno dos elementos que caracterizam a vivência dos sujeitos em torno da problemática elencada nesta pesquisa. Surgiram dela, portanto, três temáticas que, constituídas com o auxílio de um processo de triangulação de dados, amparado também pelas premissas da codificação proposta por Flick (2008), originando eixos temáticos que elucidam um determinado fenômeno.

A análise de abordagem narrativa é um movimento que contribui para estabelecer elementos que (re) criam uma história de forma projetiva, numa perspectiva de compreender o contexto a partir de histórias que caracterizam a visão de mundo de um conjunto de indivíduos. A visão de Czarniawska (1998) ajuda a compreender esse movimento como uma forma de ordenar eventos que ajudam a estruturar um contexto e que, de forma ordenada, contribuem para criar movimentos dialéticos que ajudam a prospectar o futuro. Sob essa ótica, é que a seguir os resultados da entrevista são apresentados.

\section{APRESENTAÇÃO DOS RESULTADOS}

Nesta seção é onde se apresentam os dados da análise da narrativa dos pesquisados, com o intuito de conhecer as contribuições da extensão para o desenvolvimento de competências socioemocionais em jovens que residem em espaços de vulnerabilidade social. Os entrevistados; alunos participantes do projeto e devidamente matriculados no $9^{\circ}$ ano do Ensino Fundamental de uma Escola Municipal em que o projeto é desenvolvido; serão nominados pelos códigos "ENT" e classificados de acordo com suas contribuições, que variam de 1 a 5 . Todos eles residem em espaços de vulnerabilidade social que são abarcados pelo "Território Paulo Freire", que é um lugar em que uma Universidade Comunitária do Sul Catarinense que, reitera-se, está caracterizada por "IES", desenvolve um vasto conjunto de projetos de extensão.

\subsection{Uma nova visão da universidade}

Um dos pontos de discussão em todo o campo da gestão universitária são os movimentos que se constituem para "tirar a universidade de si mesma", abrindo seu escopo de atuação para que se criem interações com a sociedade. Um dos pontos que orientam este 
processo é a extensão, notadamente reconhecida como uma das formas de fazer com que a Universidade tenha condições de atingir demandas sociais e tratá-las, de forma colaborativa, gerando resultados que tenham possam retroalimentar o ensino e a pesquisa. Contudo, há também resultados que não atingem apenas a universidade, mas também a comunidade que mantém relações com um determinado evento extensionista desenvolvido. Na medida em que isso ocorre, há condições de fortalecer os laços entre a as instituições e o entorno, criando laços de parceria e reciprocidade entre a sociedade e a "IES":

Ah, é bem legal porque eu não sabia que uma Universidade como a "IES" poderia vir até aqui. A gente é pobre, muitas vezes criado em um lugar que as pessoas que estudam não querem vir. Mas eu estou gostando muito, porque tem me mostrado que que não é assim, e um dia a gente também pode participar de tudo isso aí. (ENT1)

A visão do ENT1 desconstrói uma percepção da universidade que se restringe "a seus muros" e demonstra que a prática da extensão é um exercício bastante intenso que permite modificar um contexto de crenças enraizadas, especialmente aquelas que defendem que a universidade é um espaço "elitizado". A extensão, pelo menos a partir dos projetos desenvolvidos pela "IES", demonstra que há um exercício sendo feito para desconstruir um paradigma que ainda existe na sociedade, que entende a universidade como um espaço social restrito aos portadores de recursos estratégicos.

Nessa mesma linha, o ENT2 manifesta sua crença nas ações desenvolvidas pelo projeto, e traz um outro desafio que demonstra a responsabilidade que a IES possui neste contexto. Em suas contribuições, ele destaca que "sabe que agora pode contar com a IES para ajudar a resolver os problemas da escola e do bairro”. Essa premissa é verdadeira na medida em que um dos fundamentos da extensão é criar ações intervencionistas que possam ser assertivas em um determinado contexto, mas que não devem se confundir com o "assistencialismo", que não se configura como um papel da Universidade. Em sua natureza, tal como destaca Trindade (2000), a Universidade se constituiu para fomentar mudanças sociais por meio do ensino, da pesquisa e da extensão, aplicadas sob a ótica de um projeto institucional.

De toda a forma, a percepção dos entrevistados demonstra que a extensão proporcionou uma outra condição para a Universidade, na medida em que transformou a visão dos participantes sobre a estrutura e o funcionamento da IES. A visão dos demais entrevistados demonstra que, para os pesquisados, a Universidade é muito mais do que um 
espaço restrito, ganhando contornos de estrutura que tem a condição de contribuir para desenvolver o ambiente em que o projeto de extensão vem sendo desenvolvido:

Eu não sabia que a Universidade poderia vir até aqui e fazer essas coisas. Nesse tempo eu aprendi bastante coisa, e já sei que se eu tiver mais dúvida sobre o meu futuro, posso contar com a IES para me ajudar. (ENT3)

É legal, pois quando eu soube que a IES nos ajudaria de alguma forma a melhorar, isso me animou para fazer o ENEM um dia. Conhecemos a estrutura da IES, e tem um monte de coisas lá que funciona melhor do que o que a prefeitura fornece. (ENT4)

A partir do projeto, eu soube que a IES tinha uma estrutura que a gente pode usar para algumas questões. As clínicas, por exemplo. Fui muito bem atendido quanto estive lá. (ENT5)

Em uma análise geral da contribuição dos entrevistados, é possível perceber que a extensão contribuiu para mudar a visão dos participantes do projeto sobre a Universidade, na medida em que o projeto desenvolvido, além de auxiliá-los no desenvolvimento de novos comportamentos, contribuiu também com a (re) construção de uma nova visão sobre o papel da IES no contexto. Especialmente a partir das contribuições do ENT4 e do ENT5, o que se percebe é que, a partir do projeto, os participantes tiveram a condição de conhecer e usufruir, o que também permitiu ampliar as esperanças dos participantes quanto a aspectos do futuro, no que se refere a formação e a melhoria de suas condições de vida.

Aos envolvidos, portanto, cria-se uma nova visão da IES na medida em que ela apresentou a eles novas oportunidades de melhoria da qualidade de vida, proporcionando a comunidade ações que impactam na história de vida dos participantes do projeto e, à própria IES, elementos que tem a condição de melhorar seus currículos na medida em que a própria extensão se apresenta como uma estratégia de ensino inovadora, em função do impacto na práxis do processo de ensino e aprendizagem.

\subsection{Uma nova visão de "mim mesmo"}

Uma das características da extensão é a possibilidade de intervenção na sociedade que induz mudança das condições de vida de uma determinada comunidade. Isso ocorre em diversas esferas, de acordo com o projeto desenvolvido, e permite com que os envolvidos possam também se reconhecer como "sujeitos" que ocupam um determinado espaço social relevante. No caso do projeto desenvolvido pela "IES", aplicado em um contexto de vulnerabilidade social, o que se percebe é que o impacto causado tem a condição de (re) orientar as condições de vida de indivíduos que estão em fase de desenvolvimento. Para o ENT3, um jovem de 16 anos, a extensão teve um significado peculiar e que retrata uma condição específica do processo, que está para além das formalidades institucionais e regulatórias do ensino superior: 
Eu me senti mais confiante pois o projeto me ajudou e buscar informações sobre o meu futuro. Eu me lembro que num desses dias a minha mãe me pediu pra ir pagar uma conta e eu sempre me sentia tímido, com medo de todo mundo. Agora é diferente, eu me interesso por um monte de coisa nova e na televisão eu to (sic) gostando de assistir o jornal (ENT2)

A partir das contribuições do ENT2, percebe-se a condição explicita do projeto, especialmente da extensão, em desenvolver capacidades que estão para além das formalidades do currículo acadêmico, já que influência a qualidade de vida, a formação para a vida, a formação continuada e uma série de condições que ampliam as percepções do sujeito como um cidadão, inerido em seu contexto social, e ativo na transformação do mundo. Nesse sentido, a extensão ganha notoriedade na medida em que é um elemento substantivo no desenvolvimento de atividades que podem apresentar "o novo" para quem usufrui de seus resultados:

\begin{abstract}
Esses dias eu me interessei por ir até a sessão da câmara dos vereadores, para conhecer como funciona a atividade dos vereadores mirins. Eu comecei a me interessar pela política, e entender que o mundo é muito maior do que a direita ou a esquerda; que eu nem sabia o que era. Eu não sabia que eu poderia frequentar esses espaços (ENT3)
\end{abstract}

Além disso, em função de sua condição emancipadora, a extensão proporcionou uma visão diferente em diversos aspectos, até mesmo no estético, já que a incorporação de conhecimento de mundo também permite que o indivíduo tenha condição de se emancipar em diversas facetas de sua história. O projeto desenvolvido, além de fomentar oportunidades de conhecer a sociedade e suas diversas estruturas, também trouxe casos bastante curiosos tal como o que se apresenta nas contribuições da ENT1:

Eu passei a me olhar diferente, como uma pessoa que tem sonhos e sabe onde quer chegar na vida. Me senti mais confiante para olhar pra mim mesma e ver que eu posso ser diferente. Não tenho mais vergonha das minhas amigas, porque agora sei que eu também posso chegar onde muita gente chegou.

Outro ponto importante e que pode ser destacado, é o fato de que a extensão também contribuiu para o fortalecimento das relações familiares e sociais. Isso pode ser atribuído ao fato de que a extensão tem condições de impactar a vida das pessoas, de forma que seja possível reconstruir um espaço social crítico, impactado por problemas sociais que a Universidade tem condições de "atacar". Pelas contribuições dos ENT4 e ENT5, é possível perceber uma série de elementos que se arrolam a este fator: 
Depois do projeto, eu me vi uma pessoa que começou a entender melhor a família e um pouco das exigências que a minha mãe sempre faz. Ela não é estudante, mas depois de tudo isso eu vi que ela sabe das coisas (risos)(ENT4)

Foi legal porque eu pude valorizar mais a profissão que meu pai tem e a correria do meu irmão. $\mathrm{O}$ projeto ainda não acabou, mas eu tenho conseguido perceber o que eu tenho que fazer para ser alguém na vida e ajudar mais a minha família (ENT5)

A extensão, portanto, é um movimento bastante intenso que caminha no sentido de desenvolver competências institucionais e sociais, nos espaços e nos indivíduos, proporcionando, por meio de um fluxo interativo constante, trocas que fomentam conhecimentos e que podem aprimorar a vida dos sujeitos, a melhoria da qualidade de vida na sociedade e os currículos acadêmicos. A partir das reflexões proporcionadas por Vale (2009), além das condições sociais desenvolvidas, a extensão também fortalece os recursos metodológicos do projeto institucional, permitindo que, por meio dos projetos, ocorra o aprimoramento das ações aplicadas ao desenvolvimento do perfil do egresso esperado pelas instituições que atuam com a extensão e, neste caso, esperado também pela "IES".

4.3 As novas capacidades proporcionadas e em desenvolvimento: as competências socioemocionais como resultado da extensão

O principal objetivo do projeto está assentado em desenvolver Soft Skills para a formação cidadã e autônoma, em contextos de vulnerabilidade social, para cidadãos em idade escolar. O projeto é aplicado em uma escola municipal, que se localiza em um bairro que está situado no que a "IES" denominou de "Território Paulo Freire", que é um espaço considerado pela Universidade para desenvolver um conjunto de projetos de extensão que tenha a condição de desenvolver aquele espaço.

Nesse sentido, dentro do escopo do projeto, se destacam o desenvolvimento de oficinas, palestras, workshops e outras atividades que discutam temas transversais aos currículos da "IES" e que interajam com os componentes curriculares dos estudantes do $9^{\circ}$ ano da escola. Entre os temas das oficinas, estão o "empreendedorismo", a "cultura de paz", a "visão de mundo da política brasileira", a "gestão do conhecimento", as "discussões sobre empregabilidade no contexto da quarta revolução industrial", a "robótica" e outros temas considerados emergentes no contexto em que o colégio se localiza. Ao longo de oito oficinas já desenvolvidas, cerca de 16 participantes fizeram parte da turma, e, por meio da contribuição dos entrevistados, algumas competências socioemocionais (soft skills) foram desenvolvidas e são caracterizadas a seguir, descritas a partir de habilidades cognitivas, 
competências básicas e competências transversais, tal como é exposto também por Vale (2009).

No que se refere às habilidades cognitivas, a contribuição dos entrevistados demonstrou que as atividades desenvolvidas no workshop sobre empreendedorismo contribuíram para o desenvolvimento de habilidades cognitivas que não existiam, ou eram pouco exploradas pela escola. Em uma das contribuições, um dos entrevistados destacou que as atividades desenvolvidas e relacionadas com a educação financeira, contribuíram para o desenvolvimento de capacidades de "sensibilidade para a identificação de problemas", já que foi possível vivenciar, "na prática”, os problemas vividos na família:

Eu pude pelo menos tentar ajudar em casa. Quando a gente viu aquelas formas de organizar as finanças, eu tentei levar isso pro meu pai em casa. Ele ganha pouco, mas a gente conseguiu fazê-lo se interessar por isso. (ENT4)

Outra contribuição demonstra que houve indícios do desenvolvimento de habilidades de flexibilidade cognitiva, na medida em que alguns entrevistados evidenciaram capacidades que aprimoraram seus respectivos aprendizados. Por meio de diversas oficinas, em especial as que trataram de temas relacionados à sociedade, e ao empreendedorismo, foi possível identificar indícios de reforço nas capacidades de "auto aprendizado" e que foram reconhecidas como pontos fortes do projeto. Na visão de entrevistados, foi possível identificar que essa condição se tornou um referencial para outras atividades, inclusive para o incremento do desenvolvimento dos participantes nas atividades acadêmicas:

\footnotetext{
Hoje eu sei estudar melhor para as atividades que desenvolvo. Tenho condições de ler melhor e entender o que eu estou lendo (ENT1)

Parece que eu estou aprendendo melhor. Estou gostando de estudar mais e isso está fazendo com que as minhas atividades escolares possam render melhor (ENT2)

As minhas notas melhoraram bastante e hoje, quando eu tenho alguma dificuldade, eu me sinto melhor em pedir ajuda e sei pra quem correr (ENT3) $\mathrm{Se}$ eu conseguir manter tudo isso, vou conseguir chegar melhor no ensino médio e ter condições de entrar em uma faculdade no futuro (ENT5)
}

Outra condição percebida no projeto foi a condição proporcionada para o desenvolvimento de algumas competências básicas nos indivíduos que, de acordo com Vale (2009), Schwab (2016) e o Mitchell, Skiner e White (2010), podem fomentar um novo movimento dos indivíduos na sociedade. Esse tipo de capacidade tem a condição de tornar os sujeitos ativos em seu respectivo contexto social, permitindo, tal como estabelece Hammel 
(2009), oportunidades de adaptação na sociedade em tempos de mudança. A partir da contribuição dos entrevistados, algumas evidências deste desenvolvimento podem ser percebidas:

Eu consigo falar melhor em público. Quando tem atividade na sala, eu sou o primeiro a pedir a palavra. Eu percebi que eu aprendi a falar mais, me expressar, interagir com as pessoas...(ENT1)

Toda vez que a aula acaba eu procuro outras formas de aprender aquele conteúdo. Eu lembro do encontro que tivemos a aula sobre os potenciais da internet, e como eles podem nos ajudar. Isso tem me ajudado (ENT2)

Especificamente o ENT1 e o ENT2 demonstram a condição do desenvolvimento de duas competências básicas, destacadas nas contribuições de Mitchell, Skiner e White (2010). A Aprendizagem Ativa e a Expressão Oral, reconhecidas como competências básicas, foram citadas como evidências resultantes dos eventos do projeto:

\footnotetext{
Hoje eu consigo buscar o meu conhecimento sozinho. To (sic) aprendendo a cada dia a ler melhor e hoje eu já tenho interesse em comprar livros, o que nunca aconteceu. E hoje também entendo um pouco melhor esse negócio da política e porque todo mundo vive brigando por votar em um ou no outro. (ENT3).

Esses dias meu irmão me disse que eu tava (sic) falando igual a um apresentador de jornal. Me interesso em assistir essas coisas para conhecer melhor o mundo. Neste tempo, eu tenho percebido que me esforço para falar certo. É bonito. (ENT4).

Minha principal dificuldade era a matemática. Agora, depois daquele dia em que conversamos sobre as possibilidades que a tecnologia nos apresenta, uso os sites, o youtube; quando a internet funciona na escola; me dei conta de que posso aprender mais. (ENT5)
}

Pelas contribuições, foi possível perceber um movimento que se constrói no sentido de fomentar capacidades que são análogas ao que se espera para o contexto descrito por Schwab (2016), permitindo que os alunos, ainda em idade escolar, tenham condições de se desenvolver em um ambiente cada vez mais interdisciplinar, conectado e articulado. A extensão, portanto, cumpre um papel que está muito além dos formalismos dos currículos, proporcionando condições que tornam o cidadão cada vez mais protagonista de suas ações.

Ainda na perspectiva de novas oportunidades desenvolvidas pela extensão, outro grupo de competências pôde ser evidenciado a partir da narrativa dos entrevistados. Seguindo as linhas estabelecidas por Mitchell, Skiner e White (2010), aderentes a visão de Vale (2009), o projeto desenvolvido pela "IES" foi elemento que gerou evidências do desenvolvimento de competências sociais, competências sistêmicas e competências para jugar problemas complexos. Há, portanto, condições de afirmar que a extensão tem a capacidade de propor um aprendizado colaborativo e de fomentar capacidades que aprimorem a relação das pessoas 
com a sociedade. Nesse sentido, a contribuição dos entrevistados, demonstra com evidências algumas possibilidades:

\begin{abstract}
Em algumas situações eu consigo me controlar um pouco melhor. Eu tenho aprendido a trabalhar sobre pressão, a me organizar para cumprir os prazos na escola e a estudar. Nestes meses, parece que eu aprendi coisas práticas, que me ajudam no trabalho e a me planejar melhor (ENT1).

Acho que maturidade. Sabe, as vezes eu tenho que escolher algumas situações e eu tenho consciência de que a decisão é minha. A melhor decisão a tomar é a minha. (ENT3)
\end{abstract}

Há evidências de capacidades de análise sistêmica, uma competência prevista por Mitchell, Skiner e White (2010), na medida em que um dos entrevistados afirmou que houve a possibilidade de "avaliar com cuidado algumas situações, pois hoje eu sei que eu preciso buscar situações de 'ganha-ganha'. (ENT2). Além desta capacidade, houve também evidências do desenvolvimento de conhecimentos sobre persuasão e orientação para o serviço, que ficou explicito nas contribuições do ENT4:

\begin{abstract}
Me organizei melhor para procurar um emprego bacana. Eu consegui convencer a minha mãe de que eu teria a capacidade de estudar e trabalhar, para quem sabe empreender um dia. Falei com um amigo e convenci ele a pensar junto comigo em um negócio igual a esses que chamam de startup. (ENT4)
\end{abstract}

Sob a ótica das contribuições, o que é possível identificar é um movimento estruturado proporcionado pela extensão, alinhado com o corpus teórico destacado neste estudo, que considera a extensão como um movimento orgânico, potente e consolidado como fator gerador de capacidades institucionais e sociais. A narrativa dos entrevistados destaca evidências de contribuições proporcionadas pelo projeto desenvolvido pela "IES", que fomenta a melhoria do entorno, da própria escola, e de toda a comunidade que usufrui dos resultados destas atividades. Como contrapartida, articulam-se possibilidades de "retroalimentação" das atividades pedagógicas que são desenvolvidas nos cursos que interagem no desenvolvimento deste projeto, que no caso são os cursos de Administração e Engenharia Ambiental e Sanitária.

À extensão, portanto, é algo bastante propositivo na função de promover o protagonismo social do individuo em seu meio, contribuindo para que, em um movimento convergente, a Universidade e a Sociedade possam construir laços colaborativos e cercado em 
fundamentos pedagógicos consistentes, ampliando as formas de relacionamento entre os cidadãos, capacitando-os para a vida em sociedade e para o mundo do trabalho.

A extensão, por tudo isso, tem a condição de ajudar a construir uma história bonita, na vida de jovens que estão iniciando sua trajetória social e profissional, tal como é possível identificar no projeto em desenvolvimento pela "IES".

\section{CONSIDERAÇÕES FINAIS}

Os desafios do ensino superior brasileiro são exponenciais em virtude de um contexto altamente desafiador, que enseja condições que estão alterando a identidade "pedagógica" das instituições. Os percursos curriculares, materializados em currículo; que por sua vez são desdobrados em matrizes curriculares e práticas pedagógicas; buscam ampliar o escopo de atividades dos acadêmicos (docentes e discentes). Nesse sentido, a extensão emerge como responsável por um papel fundamental, que atualmente é reconhecido como um dos principais elementos que podem proporcionar atividades inovadoras e disruptivas no ensino superior. Em função da condição da extensão de ampliar as relações das instituições com a comunidade, ela se apresenta como sendo essencial na prática pedagógica de todas as instituições de ensino superior.

Este artigo discutiu as principais contribuições da extensão para o desenvolvimento de competências socioemocionais em jovens que residem espaços de vulnerabilidade social. Por intermédio do estudo de um projeto de extensão, desenvolvido no contexto da "IES", foi possível identificar contribuições na formação cidadã de jovens que estão percorrendo seu caminho educacional. Os resultados, obtidos sob a ótica de um estudo narrativo de característica episódica, tal como exposto por Flick (2008), apresenta um conjunto de elementos relativos a uma narrativa de situações que explicitam o que ocorre em um determinado contexto, permitindo a exposição de uma realidade a partir da vivência e da hermenêutica do próprio sujeito.

Por meio do processo de codificação, foi possível chegar aos eixos que explicam as formas pelas quais a extensão contribui com o desenvolvimento das capacidades alinhadas com o contexto da quarta revolução industrial.

Entre as contribuições, emergiu "uma nova visão da universidade", na medida em que foi possível elucidar o fato de que a extensão desconstruiu uma visão elitizada da "IES", onde a Instituição ampliou seu escopo de atividade para oferecer condições de melhoria para a vida das pessoas. À superfície, também veio a condição do desenvolvimento de uma nova visão sobre o sujeito, pois a extensão, por meio do projeto desenvolvido, proporcionou 
"autoconhecimento" aos participantes entrevistados, o que também é um indício de uma capacidade esperada pelo contexto da quarta revolução industrial.

Por fim, foi possível identificar um conjunto de competências que se alinham a perspectiva da quarta revolução industrial, desenvolvidas a partir das atividades propostas pelo projeto e que permitiram com que os participantes da proposta pudessem se reconhecer como sujeitos ativos e protagonistas de um movimento de mudanças.

Do ponto de vista das contribuições, percebe-se algumas que podem ser destacadas. As acadêmicas emergem na medida em que os resultados ajudam a ampliar o quantitativo de estudos sobre a extensão, que numa perspectiva acadêmica ainda são escassos. Dessa forma, este trabalho contribui para aumentar as possibilidades de discussão deste tema, elementar para programas de inovação curricular e pedagógica. Do ponto de vista de gestão, alguns elementos também podem ser evidenciados, com destaque para o auxílio proporcionado pelo artigo na gestão dos projetos pedagógicos e no desenvolvimento de novas práticas pedagógicas que tenham a condição de aprimorar os projetos pedagógicos.

Aos trabalhos futuros, recomendam-se as investigações a respeito dos impactos da extensão nos currículos e na formação pedagógica dos docentes, permitindo também que seja possível (re) conhecer a extensão como prática pedagógica e estratégia de aprendizagem.

Ademais, reconhecendo a extensão como um elemento importante na discussão da inovação curricular, espera-se que este trabalho também contribua com as discussões de espaços reconhecidos como instancias de discussão da extensão, como é o caso de FORPROPEX. Isso se dá especialmente pela condição de possibilidades, já que o tema tem sido discutido em diversos outros contextos:

Higher education leaders have an obligation to serve a leadership role as drivers of economic and social progress in their regions and we are increasingly seeing universities in Mexico and across Latin America take this commitment seriously. (GARCIA, 2019)

\section{REFERÊNCIAS}

AIRES, Rover. W. A.; KEMPNER-MOREIRA, Fernanda. K.; FREIRE, Patrícia. S. Indústria 4.0: competências requeridas aos profissionais da quarta revolução industrial. ANAIS. 
In: CONGRESSO INTERNACIONAL DE CONHECIMENTO E INOVAÇÃO (CIKI). Foz do Iguaçu. 2017.

BALASHOVA, E. S.; GROMOVA, E. A. Agile manufacturing as a promising concept for Russian industry. In: IOP Conference Series: Materials Science and Engineering. IOP Publishing, 2018.

BARDIN, Laurence. Contentanalysis. São Paulo: Livraria Martins Fontes, 1977.

BRASIL. Resolução No 7, DE 18 de dezembro de 2018. Estabelece as Diretrizes para a Extensão na Educação Superior Brasileira e regimenta o disposto na Meta 12.7 da Lei. N. 13.005/2014, que aprova o Plano Nacional da Educação - PNE 2014-2024 e dá outras providencias. Ministério da Educação Conselho Nacional de Educação. Câmara De Educação Superior. Brasília. 2018.

CALANCA, Federica et al. Responsible team players wanted: an analysis of soft skill requirements in job advertisements. EPJ Data Science, v. 8, n. 1, p. 13, 2019.

CORBIN, Juliet; STRAUSS, Anselm. Strategies for qualitative data analysis. Basics of Qualitative Research. Techniquesand procedures for developinggroundedtheory, v. 3, 2008.

CRESWELL, John W. Investigação Qualitativa e Projeto de Pesquisa-: Escolhendo entre Cinco Abordagens. PensoEditora, 2014.

CZARNIAWSKA, Bernard. J. A narrative approach to organization studies. London: Sage, 1998.

DAS, Anindita; DAS, Biswa. Economic and Fiscal Impacts of Refugees in Central Iowa: Opportunities for University Extension. JournalofExtension, v. 57, n. 2, p. n2, 2019.

FLICK, Uwe. Introdução à pesquisa qualitativa-3. Artmed editora, 2008.

FULGA, Simina; DAVIDESCU, Arjana; EFFENBERGER, Ira. Conceptual approach for an in-line quality control system in Additive Manufacturing Powder Bed Fusion processes. In: MATEC Web of Conferences. EDP Sciences, 2017.

GARCIA, Fernando León. How global HE collaboration can benefit local communities. University World News. The Global Window on Higher Education.

Disponívelem:https://www.universityworldnews.com/post.php?story=2019052314112421. Acessoem 21/05/2019.

GEORGIOU, Konstantina; GOURAS, Athanasios; NIKOLAOU, Ioannis. Gamification in employee selection: The development of a gamified assessment. InternationalJournalofSelectionand Assessment, 2019.

HAMEL, Gary. O que importa agora: como construir empresas à prova de fracassos. Elsevier Brasil, 2012. 
HENDERSON, Meg. A Library's Partnership Experience with University Extension to Provide Program Content. Journal of Library Administration, v. 59, n. 4, p. 409-421, 2019.

JAGANNATHAN, Radha; CAMASSO, Michael J.; DELACALLE, Maia. Promoting cognitive and soft skills acquisition in a disadvantaged public school system: Evidence from the Nurture thru Nature randomized experiment. Economics of Education Review, v. 70, p. 173-191, 2019.

LIVENTSOVA, E. Yu; RUMYANTSEVA, T. B.; SYRYRAMKINA, E. G. Social and humanistic aspects for the training of technical professionals. In: IOP Conference Series: Materials Science and Engineering. IOP Publishing, 2019. p. 012019.

MITCHELL, Geana W.; SKINNER, Leane B.; WHITE, Bonnie J. Essential Soft Skills for Success in the Twenty-First Century Workforce as Perceived by Business Educators. Delta Pi Epsilon Journal, v. 52, n. 1, 2010.

MORGAN, Gareth. Paradigms, metaphors, and puzzle solving in organization theory. Administrativesciencequarterly, p. 605-622, 1980.

NUNES, Ana Lucia de Paula Ferreira; DA CRUZ SILVA, Maria Batista. A extensão universitária no ensino superior e a sociedade. Mal-Estar e Sociedade, v. 4, n. 7, p. 119-133, 2011.

RANA, Md Rafiqul Islam; HA-BROOKSHIRE, Jung. New conceptual framework for fashion business ideation, negotiation, and implementation undergraduate curricula for sustainable development. International Journal of Fashion Design, Technology and Education, v. 12, n. 2, p. 140-148, 2019.

RODRIGUES, Andréia Lilian Lima; COSTA, Carmen Lucia Neves do Amaral; PRATA, Michelle Santana; BATALHA, Taila Beatriz Silva; PASSOS NETO, Irazano de Figueired. Contribuições da extensão universitária na sociedade. Caderno de Graduação-Ciências Humanas e Sociais-UNIT, v. 1, n. 2, p. 141-148, 2013.

SCHWAB, Klaus. The fourth industrial revolution. Currency, 2017.

SRIDHARAN, Bhavani; BOUD, David. The effects of peer judgements on teamwork and self-assessment ability in collaborative group work. Assessment \&Evaluation in

HigherEducation, p. 1-16, 2019.

TRINDADE, Hélgio. Saber e poder: os dilemas da universidade brasileira. Estudos Avançados, v. 14, n. 40, p. 122-133, 2000.

TSENG, Hungwei; YI, Xiang; YEH, Hsin-Te. Learning-related soft skills among online business students in higher education: Grade level and managerial role differences in selfregulation, motivation, and social skill. Computers in HumanBehavior, v. 95, p. 179-186, 2019. 
VALE, Vera Do. Do tecer ao remendar: os fios da competência socio-emocional. EXEDRA: Revista Científica, n. 2, p. 129-146, 2009.

XIONG, Gang; TONGKAI, Ji; XIPENG, Zhang; FENGHUA, Zhu; WENJING, Liu. Cloud operating system for industrial application. In: 2015 IEEE International Conference on Service Operations And Logistics, And Informatics (SOLI). IEEE, 2015. 